\title{
LOW CORONARY PERFUSION PRESSURE IS ASSOCIATED WITH ENDOCARDIAL FIBROSIS IN A RAT MODEL OF VOLUME OVERLOAD CARDIAC HYPERTROPHY
}

\author{
Maria Carolina Guido, Márcia Kiyomi Koike and Clovis de Carvalho Frimm
}

GUIDO MC et al. Low coronary perfusion pressure is associated with endocardial fibrosis in a rat model of volume overload cardiac hypertrophy. Rev. Hosp. Clín. Fac. Med. S. Paulo 59(4):228-235, 2004.

Left ventricular hypertrophy following volume overload is regarded as an example of cardiac remodeling without increased fibrosis accumulation. However, infarction is associated with increased fibrosis within the noninfarcted, hypertrophied myocardium, particularly in the subendocardial regions. It is conceivable to suppose that, as also occurs postinfarction, low coronary driving pressure may also interfere with accumulation of myocardial fibrosis following aortocaval fistula.

PURPOSE: To investigate the role of acute hemodynamic changes in subsequent deposition of cardiac fibrosis in response to aortocaval fistula.

METHOD: Aortocaval fistula were created in 4 groups of Wistar rats that were followed over 4 and 8 weeks: aortocaval fistula 4 and aortocaval fistula 8 (10 rats each) and their respective controls (sham-operated controls - Sh), Sh4 and Sh8 (8 rats each). Hemodynamic measurements were performed 1 week after surgery. Hypertrophy and fibrosis were quantified by myocyte diameter and collagen volume fraction at the end of follow up.

RESULT: Compared with Sh4 and Sh8, pulse pressure, left ventricular end-diastolic pressure, and +dP/dt were higher in aortocaval fistula 4 and aortocaval fistula 8 , but $-\mathrm{dP} / \mathrm{dt}$ was similar. Coronary driving pressure $(\mathrm{mm} \mathrm{Hg})$, used as an estimate of perfusion pressure, was lower in aortocaval fistula $8(52.6 \pm 4.1)$ than in Sh8 $(100.8 \pm 1.3)$, but comparable between aortocaval fistula $4(50.0 \pm 8.9)$ and Sh4 $(84.8 \pm 2.3)$. Myocyte diameter was greater in aortocaval fistula 8 , whereas interstitial and subendocardial fibrosis were greater in aortocaval fistula 4 and aortocaval fistula 8 . Coronary driving pressure correlated inversely and independently with subendocardial fibrosis $\left(r^{2}=.86, P<.001\right)$, whereas left ventricular systolic pressure $\left(r^{2}=0.73\right.$, $P=.004)$ and end-diastolic pressure $\left(r^{2}=0.55, P=012\right)$ correlated positively and independently with interstitial fibrosis.

CONCLUSION: Coronary driving pressure falls and ventricular pressures increase early after aortocaval fistula and are associated with subsequent myocardial fibrosis deposition.

KEY WORDS: Myocardial fibrosis. Aortocaval fistula. Coronary driving pressure. Volume overload. Cardiac remodeling.

An increase in myocyte volume accompanied by an expansion of the extracellular matrix characterize the development of myocardial hypertrophy in response to cardiac overload. ${ }^{1,2,3}$ The positive effect is the preservation of cardiac performance by preventing an increase in myocardial oxygen consumption. ${ }^{4,5,6}$
Although initially beneficial, hypertrophy may ultimately result in

From the Laboratory of Medical Investigation 51, Clinical Emergencie Discipline, Hospital das Clínicas, Faculty of Medicine, University of São Paulo - São Paulo/SP, Brazil.

E-mail: macguido@terra.com.br Received for publication on July 31, 2003. cardiac failure. ${ }^{1,7,8}$ One of the potential mechanisms involved is the advent of myocardial ischemia, which may follow a disproportionate growth of myocytes relative to coronary vessels. ${ }^{9,10,11}$ Recurrent ischemic episodes predictably result in myocyte necrosis and scar formation. ${ }^{12,13,14}$

In different animal models of car- 
diac hypertrophy, it has been repeatedly documented that the collagen volume fraction (CVF) increases. ${ }^{15,16,17,18}$ Two main forms of fibrillar collagen accumulation are currently acknowledged: reactive and reparative fibrosis. ${ }^{19,20,21,22}$ Reactive interstitial fibrosis follows the development of pressure overload hypertrophy, in particular, and is characterized by an increased accumulation of collagen fibers intermingled among myocytes. ${ }^{16,23}$ Reparative fibrosis results from myocyte loss and represents wound healing scarring, such as occurs following myocardial infarction. ${ }^{12,15}$

In eccentric hypertrophic response to volume overload, myocyte growth and fibrillar collagen accumulation appear to develop in a proportional manner. ${ }^{24-26}$ However, increased fibrosis has recently been reported in cases of volume overload. ${ }^{10,11,27,28}$ In infarction, the development of interstitial and subendocardial (SE) fibrosis within noninfarcted myocardium has been recognized. ${ }^{12,29,30}$ In this case, SE fibrosis appears to represent a repair process in response to persistent ischemia in this region, since the coronary driving pressure (CDP) has been documented to be low during the early phases after infarction ${ }^{12}$.

It is conceivable to suppose that a similar mechanism might have a role in collagen fiber accumulation in volume overload hypertrophy. If the initial hemodynamic burden affects the CDP, as already demonstrated for large infarcts, ${ }^{12} \mathrm{SE}$ fibrosis is likely to supervene. Furthermore, interstitial fibrosis might also follow if, in addition to volume overload, afterload were increased during hypertrophy development.

In experimental cardiac hypertrophy, hemodynamic monitoring during surgical procedures is rarely performed. Consequently, the effects of acute hemodynamic changes on subsequent myocardial remodeling are currently undetermined.

The aim of the present study is to investigate in a experimental model of volume overload cardiac hypertrophy: 1) whether or not there is increased cardiac collagen accumulation, 2) the distribution and type of fibrosis, and 3) the potential role of acute hemodynamic changes in the subsequent development of myocardial fibrosis.

\section{METHOD}

\section{Animals and groups}

Wistar rats weighing 280 to $350 \mathrm{~g}$ were used. All procedures were carried out in accordance with the norms of the Brazilian College of Animal Experiments and conformed to the "Guide for the Care and Use of Laboratory Animals". Our Institutional Ethical Committee approved the protocol (CAPPesq, 160/02).

Four groups of animals with surgically created aortocaval fistula (ACF) were constituted: ACF4 and ACF8, 10 rats each, and their respective shamoperated controls (Sh), Sh4 and Sh8, 8 rats each, followed over 4 and 8 weeks, respectively.

\section{Experimental model}

Surgical procedures were carried out using a modified technique that has been previously described ${ }^{31,32}$. Under $10 \%$ chloral hydrate anesthesia $(300 \mathrm{mg} / \mathrm{kg} \text {, intraperitoneally })^{33}$ and positive pressure ventilation (Harvard - Rodent ventilator - Model 683 South Natick, Massachusetts, EUA), a median laparotomy was performed, and the abdominal aorta and the inferior vena cava were identified and isolated from neighboring structures underneath the emergence of the renal arteries. Arterial and venous blood flow was briefly interrupted with the aid of vascular clamps to permit the insertion of an 18-gauge needle into the aorta.
The needle was carefully advanced, and the posterior aortic wall was punctured 3 to 4 times to the inside of the vena cava. After removing the needle, homeostasis was conducted with local application of super glue. The abdominal wall was closed and the animals returned to their cages after full recovery.

The mortality rate was $8 \%$ immediately, 29\% 48 hours after surgery, and $23 \%$ during long-term follow up. Fistula permeability was assessed daily with a pediatric stethoscope.

\section{Hemodynamic measurements}

One week after surgery, surviving rats were anesthetized again and submitted to simultaneous systemic and cardiac hemodynamic measurements (hemodynamics—phase 1). Briefly, a $0.05 \mathrm{~mm}$ polyvinyl chloride catheter was inserted through the right carotid artery into the ascending aorta and advanced into the left ventricle (LV). Another catheter was inserted through the jugular vein into the superior vena cava and advanced into the right atrium. Also, a $0.01 \mathrm{~mm}$ catheter was introduced through the left femoral artery and advanced into the descending abdominal aorta. The catheters were connected to pressure transducers and coupled with a calibrated pre-amplifier (General Purpose Amplifier 4 - model 2, Stemtech Inc. WI, USA). Pressure tracings were recorded and analyzed using a computerized system processor (Windaq - AT/Codas, Dataq Instruments Inc., OH, USA).

The following parameters were evaluated: systemic systolic arterial pressure $(\mathrm{mm} \mathrm{Hg})$ and systemic diastolic arterial pressure $(\mathrm{mm} \mathrm{Hg}), \mathrm{LV}$ systolic pressure (mm Hg), LV enddiastolic pressure $(\mathrm{mm} \mathrm{Hg})$, and right mean atrial pressure $(\mathrm{mm} \mathrm{Hg})$. In addition, the positive and the negative derivatives of $L V$ pressure with respect to time $\left(+\mathrm{dP} / \mathrm{dt}, \mathrm{mm} \mathrm{Hg} \cdot \mathrm{s}^{-1}\right.$ and $-\mathrm{dP} / \mathrm{dt}$, 
$\mathrm{mm} \mathrm{Hg} \cdot \mathrm{s}^{-1}$ ) were obtained as measures of LV systolic and diastolic function, respectively.

Pulse pressure ( $\mathrm{mm} \mathrm{Hg}$ ) was calculated as the difference between systemic systolic arterial pressure and diastolic arterial pressure and used as a measure of fistula size.

CDP ( $\mathrm{mm} \mathrm{Hg}$ ) calculated by the difference between systemic diastolic arterial pressure and LV end-diastolic pressure was used as an estimate of myocardial perfusion pressure. ${ }^{34}$

After 4 and 8 weeks of follow up, before sacrifice, rats were again anesthetized, and the femoral artery was catheterized for new systemic systolic arterial pressure, diastolic arterial pressure, and pulse pressure determinations (hemodynamics-phase 2).

All measurements corresponded to the mean value of each hemodynamic parameter continuously recorded during a 10-minute period after stabilization of the pressure curves.

\section{Anatomic and morphometric study}

The animals were sacrificed using a $100 \mathrm{mM} \mathrm{CdCl} \mathrm{Cl}_{2}$ solution and were perfusion-fixed with $10 \%$ formalin under a perfusion pressure corresponding to the systemic diastolic arterial pressure in vivo. The heart, lungs, and liver were removed, cleaned, and weighed. The dry weight of the lungs and liver were used for calculating the percentage of water content in each tissue, which was used as an estimate of congestive heart failure. After determining heart / body weight $\left(\mathrm{g} \cdot \mathrm{kg}^{-1}\right)$, the right and the left atrium were carefully trimmed out and weighed separately.

A 1 to $2 \mathrm{~mm}$ coronal slice of the heart, including both ventricles, was cut at the equatorial plane to obtain $7 \mu \mathrm{m}$ thick paraffin-embedded tissue sections. After being stained with hematoxylin and eosin (HE) and picrosirius red, ${ }^{35}$ these sections underwent morphometric analysis using an image analysis system (Leica Q500 iW, Leica Imaging Systems 1td., Cambridge, UK).

At first, each HE tissue section was visualized under a macro lens $(28 \mathrm{~mm}$, Tamron, Japan) to permit the determination of LV wall thickness and LV cavity dimension, both expressed as tissue areas $\left(\mu \mathrm{m}^{2}\right)$. Subsequently, LV myocyte hypertrophy was estimated under a 100x microscopic objective by measuring myocyte transversal diameter around the nucleus $(\mu \mathrm{m})$.

Fibrillar collagen was identified in the picrosirius red-stained sections by its red color. Under a 40x microscopic objective, an estimate of CVF was determined to be the mean percentage of red-stained connective tissue areas per total myocardial area in each microscopic field (\%). The CVF was addressed separately in 2 distinct regions: the inner third of the LV, corresponding to the subendocardium, and the medium third of the interventricular septum. An average of 15 to 20 fields was examined in each of these 2 myocardial regions.

Perivascular collagen (\%) was calculated separately as the ratio of picrosirius red-positive stained areas around microvessels to luminal perimeter. Only 50 to $200 \mu \mathrm{m}$ arterioles with major to minor diameter ratio $<0.60$ were computed.

Table 1 - Hemodynamic data obtained at one week following aortocaval fistula creation (hemodynamics - phase 1) of groups Sh4, ACF4, Sh8, and ACF8.

\begin{tabular}{lccccc}
\hline & Sh4 & ACF4 & Sh8 & ACF8 & $P$ \\
$\mathrm{~N}$ & 8 & 10 & 8 & 10 & \\
\hline SAP $(\mathrm{mm} \mathrm{Hg})$ & $115.3 \pm 2.7$ & $104.8 \pm 5.9^{*}$ & $123.3 \pm 1.0$ & $104.0 \pm 3.7^{*}$ & .001 \\
DAP $(\mathrm{mm} \mathrm{Hg})$ & $91.8 \pm 2.3$ & $68.0 \pm 7.0$ & $108.0 \pm 1.1$ & $66.6 \pm 3.8^{*}$ & $<.001$ \\
PP $(\mathrm{mm} \mathrm{Hg})$ & $23.5 \pm 2$ & $36.8 \pm 2.6^{*}$ & $15.3 \pm 1.4$ & $37.4 \pm 3.3^{*}$ & $<.001$ \\
LVSP $(\mathrm{mm} \mathrm{Hg})$ & $113.1 \pm 3.3$ & $124.1 \pm 6.2$ & $117.6 \pm 1.8$ & $150.2 \pm 5.9^{*}$ & $<.001$ \\
LVEDP $(\mathrm{mm} \mathrm{Hg})$ & $7.0 \pm 0.1$ & $18.1 \pm 3.4^{*}$ & $7.2 \pm 0.3$ & $14.0 \pm 1.5^{*}$ & $<.001$ \\
+dP/dt $\left(10^{3} \mathrm{~mm} \mathrm{Hg} \cdot \mathrm{s}^{-1}\right)$ & $4.0 \pm 0.2$ & $5.8 \pm 0.6^{*}$ & $3.9 \pm 0.1$ & $6.2 \pm 0.5^{*}$ & $<.001$ \\
$-\mathrm{dP} / \mathrm{dt}\left(10^{3} \mathrm{~mm} \mathrm{Hg} \cdot \mathrm{s}^{-1}\right)$ & $3.8 \pm 0.2$ & $4.5 \pm 0.4$ & $3.9 \pm 0.2$ & $4.1 \pm 0.5$ & .530 \\
RAP $(\mathrm{mm} \mathrm{Hg})$ & $5.3 \pm 0.3$ & $8.4 \pm 0.6^{*}$ & $5.1 \pm 0.2$ & $8.0 \pm 1.1^{*}$ & $<.001$ \\
HR (beats $\left.\cdot \mathrm{min}^{-1}\right)$ & $370.0 \pm 13.3$ & $348.5 \pm 25.1$ & $373.6 \pm 7.3$ & $344.4 \pm 11.8$ & .262 \\
\hline
\end{tabular}

SAP, systemic systolic arterial pressure; DAP, systemic diastolic arterial pressure; PP, pulse pressure; LVSP, left ventricular systolic pressure; LVEDP, left ventricular end-diastolic pressure; $+\mathrm{dP} / \mathrm{dt}$, positive derivative of left ventricular pressure; $-\mathrm{dP} / \mathrm{dt}$, negative derivative of left ventricular pressure; RAP, right mean atrial pressure; HR, heart rate; *, $P<.05$ ACF vs respective Sh. 
pressure in $\mathrm{ACF} 4$, systemic arterial pressures were statistically lower in both ACF4 and ACF8 than in their respective Sh controls. Accordingly, pulse pressure was statistically greater in ACF than in Sh groups.

Intraventricular pressures showed higher LV systolic pressure in ACF8 than in Sh8 and higher LV enddiastolic pressure in ACF4 than in Sh4 and in ACF8 than in Sh8.

$\mathrm{LV}$ function showed greater $+\mathrm{dP} / \mathrm{dt}$ in both ACF groups than in their respective Sh controls and comparable $-\mathrm{dP} / \mathrm{dt}$.

Right mean atrial pressure was statistically higher in both ACF than in Sh, whereas heart rate did not differ.

As for LV perfusion pressure (Figure 1), CDP was lower in ACF, although this was statistically significant only with regards to the comparison between ACF8 and Sh8.

\section{Hemodynamics - Phase 2}

At the end of follow up (Table 2), while systemic systolic arterial pressure was comparable between both ACF4 and ACF8 and their respective Sh controls, systemic diastolic arterial pressure was statistically lower. Accordingly, pulse pressure was significantly higher in both ACF groups than in their Sh controls. Again, heart rate was comparable among groups.

\section{Anatomy and Morphometry}

Table 3 depicts the anatomic and morphometric data. While initial weights of rats were comparable in all groups, final weights were greater in groups followed over 8 weeks than in groups followed over 4 weeks.

The percent of water in lungs and liver as well as the relative total heart and left atrium weights were not statistically different among groups.

While relative left atrium weight did not differ between ACF and Sh

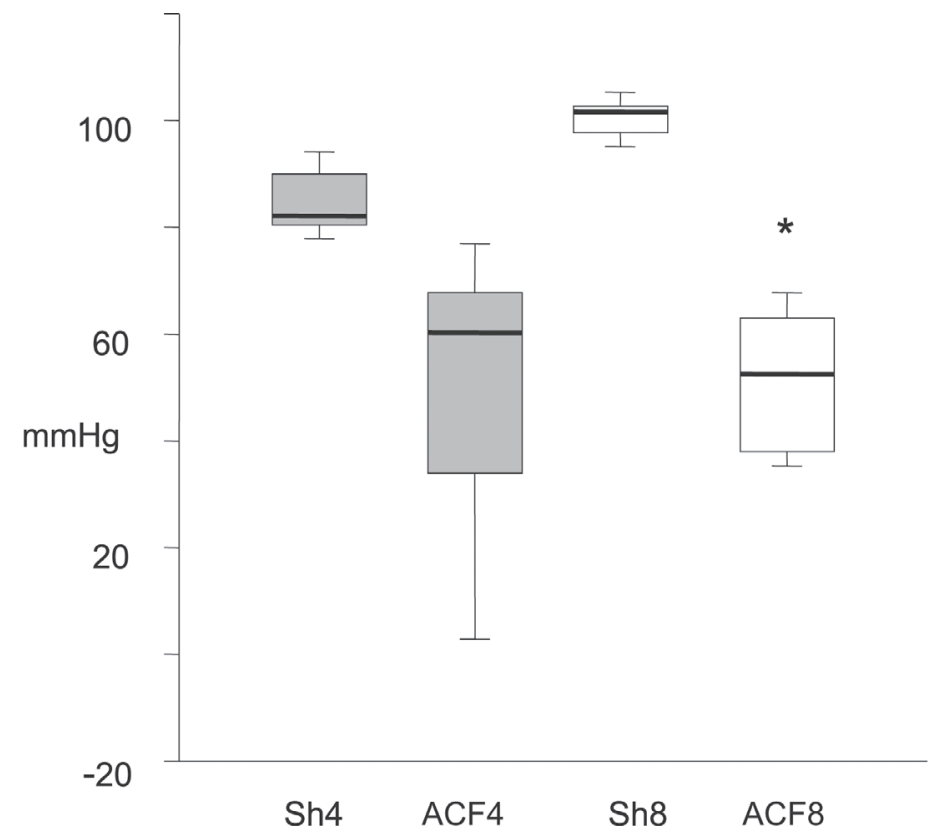

Figure 1 - Left ventricular coronary driving pressure in Sh4, ACF4, Sh8, and ACF8 groups. *, $P<.05$ ACF vs respective Sh.

Table 2 - Hemodynamic data obtained at 4 and 8 weeks following aortocaval fistula creation (hemodynamics-phase 2) of groups Sh4, ACF4, Sh8, and ACF8.

\begin{tabular}{lccccc}
\hline & Sh4 & ACF4 & Sh8 & ACF8 & $P$ \\
$\mathrm{~N}$ & 8 & 10 & 8 & 10 & \\
\hline SAP (mm Hg) & $125.5 \pm 1.9$ & $120.7 \pm 7.9$ & $128.8 \pm 1.7$ & $116.4 \pm 6.1$ & .414 \\
DAP (mm Hg) & $94.3 \pm 2.4$ & $71.2 \pm 5.5^{*}$ & $94.0 \pm 2.1$ & $67.7 \pm 5.2^{*}$ & $<.001$ \\
PP (mm Hg) & $31.3 \pm 1.6$ & $49.5 \pm 5.2^{*}$ & $34.8 \pm 2.7$ & $48.7 \pm 5.0^{*}$ & .007 \\
HR (beats min $\left.^{-1}\right)$ & $373.5 \pm 12.8$ & $337.0 \pm 32.3$ & $386.8 \pm 10.7$ & $343.6 \pm 20.6$ & .542 \\
\hline
\end{tabular}

SAP, systemic systolic arterial pressure; DAP, systemic diastolic arterial pressure; PP, pulse pressure; HR, heart rate; ${ }^{*}, P<.05$ ACF vs.respective Sh.

Table 3 - Heart and body weights, percent of organ water weight, myocyte diameter, and collagen volume fraction of groups Sh4, ACF4, Sh8, and ACF8.

\begin{tabular}{|c|c|c|c|c|c|}
\hline $\mathrm{N}$ & $\begin{array}{c}\text { Sh4 } \\
8\end{array}$ & $\begin{array}{c}\mathrm{ACF} 4 \\
10\end{array}$ & $\begin{array}{c}\text { Sh } 8 \\
8\end{array}$ & $\begin{array}{c}\text { ACF8 } \\
10\end{array}$ & $P$ \\
\hline IAW (g) & $315.9 \pm 7.2$ & $309.2 \pm 9.6$ & $297.8 \pm 2.6$ & $322.0 \pm 6.8$ & .071 \\
\hline FAW (g) & $367.5 \pm 11.4$ & $357.0 \pm 7.7$ & $414.7 \pm 15.3^{=}$ & $421.7 \pm 6.3^{=}$ & $<.001$ \\
\hline$\% \mathrm{H}_{2} \mathrm{O}_{\mathrm{Lu}}$ & $84.1 \pm 0.8$ & $82.0 \pm 0.6$ & $85.2 \pm 1.0$ & $82.2 \pm 1.2$ & .061 \\
\hline$\% \mathrm{H}_{2} \mathrm{O}_{\mathrm{Li}}$ & $74.6 \pm 0.3$ & $72.4 \pm 0.8$ & $72.6 \pm 0.8$ & $71.2 \pm 1.9$ & .174 \\
\hline HW & $5.2 \pm 0.2$ & $5.5 \pm 0.5$ & $4.3 \pm 0.2$ & $5.8 \pm 0.7$ & .07 \\
\hline LAW & $0.09 \pm 0.01$ & $0.14 \pm 0.02$ & $0.11 \pm 0.01$ & $0.16 \pm 0.02$ & .059 \\
\hline RAW & $0.06 \pm 0.01$ & $0.13 \pm \pm 0.02 *$ & $0.07 \pm 0.01$ & $0.15 \pm 0.04$ & .001 \\
\hline LV WT $\left(\mu \mathrm{m}^{2}\right)$ & $42.3 \pm 3.3$ & $35.7 \pm 2.2$ & $51.9 \pm 4.3$ & $31.0 \pm 2.3^{*}$ & .001 \\
\hline $\mathrm{LV}$ CD $\left(\mu \mathrm{m}^{2}\right)$ & $36.1 \pm 6.5$ & $25.4 \pm 3.5$ & $37.2 \pm 4.2$ & $39.8 \pm 8.2$ & .323 \\
\hline MY $\phi(\mu \mathrm{m})$ & $6.7 \pm 0.05$ & $9.2 \pm 0.26^{*}$ & $6.2 \pm 0.07$ & $10.1 \pm 0.19 *$ & $<.001$ \\
\hline SE CVF (\%) & $4.6 \pm 0.47$ & $26.7 \pm 5.5^{*}$ & $4.0 \pm 0.79$ & $25.6 \pm 3.5^{*}$ & $<.001$ \\
\hline IVS CVF (\%) & $5.5 \pm 0.61$ & $13.7 \pm 1.4 *$ & $4.7 \pm 0.61$ & $13.4 \pm 1.3^{*}$ & $<.001$ \\
\hline PVC (\%) & $13.7 \pm 1.3$ & $15.4 \pm 1.5$ & $14.2 \pm 0.7$ & $16.5 \pm 2.9$ & .834 \\
\hline
\end{tabular}

IAW, initial animal weight; FAW, final animal weight; $\% \mathrm{H}_{2} \mathrm{O}_{\mathrm{Lu}}$, percentage of water in lungs; \% $\mathrm{H}_{2} \mathrm{O}_{\mathrm{Li}}$, percentage of water in liver; $\mathrm{HW}$, relative heart weight; RAW, relative right atrium weight; LAW, relative left atrium weight; LV WT, left ventricular wall thickness; LV CD, left ventricular cavity dimension; MY $\phi$, myocyte diameter; SE CVF, subendocardial collagen volume fraction; IVS CVF, interventricular septum collagen volume fraction; PVC, perivascular collagen; *, $P<.05$ ACF vs respective $\mathrm{Sh} ;=, P<.058$ vs respective 4. 
groups, relative right atrium weight was statistically greater in ACF4 than in Sh4.

While LV wall thickness did not statistically differ between ACF4 and $\mathrm{Sh} 4$ groups, it was lower in ACF8 than in Sh8. The cavity dimension of the $\mathrm{LV}$ did not differ between $\mathrm{ACF}$ and $\mathrm{Sh}$ groups.

At the microscopic level, myocyte diameter was statistically greater in both ACF4 and ACF8 than in their respective Sh controls.

Thus, excentric left ventricular hypertrophy was manifested in ACF8 by larger myocyte diameter and smaller wall thickness than in Sh8, with comparable cavity dimension.

As for the extracellular matrix compartment, CVF measured within each of the two regions examined, interventricular septum and SE, was statistically greater in both ACF groups than in their respective Sh controls. Perivascular collagen did not differ among groups.
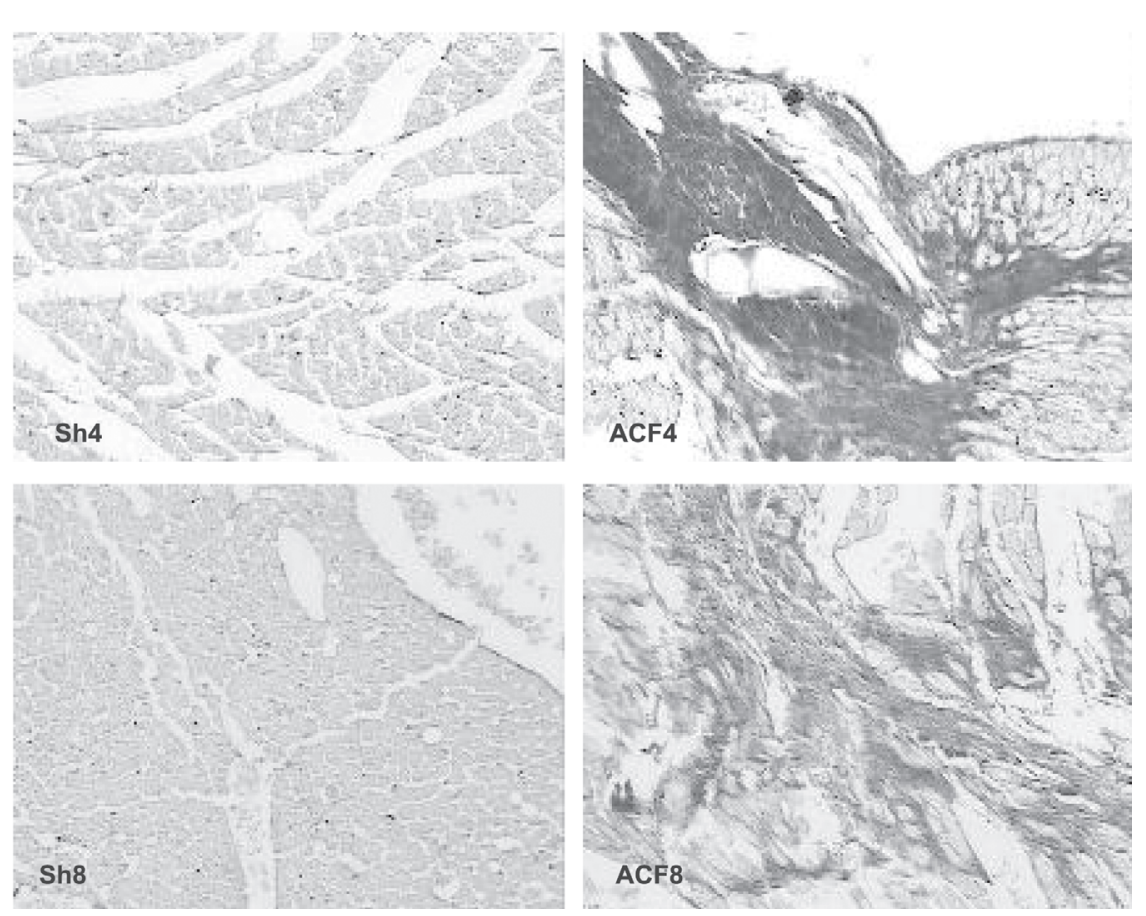

Figure 2 - Photomicrographs of picrosirius red-stained tissue sections under a 40x magnification featuring the left ventricular subendocardial region representative of each one of the 4 groups of rats studied: Sh4, ACF4, Sh8, and ACF8. Subendocardial collagen deposition in hearts of ACF animals is illustrated by a marked increase in picrosirius red-stained positive areas.
In Figure 2 is portrayed the hallmark of the histological findings found in ACF rats, represented by LV SE fibrosis.

\section{Hemodynamic determinants of left ventricular fibrosis}

\section{Subendocardial fibrosis}

The SE fibrosis of hearts examined 8 weeks after experimental surgery correlated positively with pulse pressure $(r=0.85, P<.001)$, LV systolic pressure $(r=0.67, P=.038)$, and LV end-diastolic pressure $(r=0.74, P=$ .001 ) measured 1 week after surgery. In addition, SE fibrosis at 8 weeks correlated inversely with systemic systolic arterial pressure $(r=-0.69, P=.003)$, systemic diastolic arterial pressure $(r=$ $-0.91, P<.001)$, and CDP $(r=-0.93$, $P<.001)$.

Among all, only CDP independently predicted SE fibrosis $\left(r^{2}=0.86\right.$, $\mathrm{SE}=0.0536, P<.001)$ at 8 weeks. from the vascular shunt in the present study.

In contrast with our findings, previous studies reported reductions of 
LV systolic pressure, ${ }^{17,18,36}$ indicating the presence of cardiac dysfunction. It has to be emphasized that hemodynamic monitoring was performed before sacrifice in most former studies, when cardiac dysfunction has had enough time to supervene. Our 1week hemodynamic results demonstrate that diastolic function was preserved despite the elevation of LV enddiastolic pressure. This may be explained by an enlarged LV dimension and thus increased preload, which may have in part contributed to the hypercontractility found, through the Starling mechanism. Since morphometry was performed only 4 and 8 weeks after the hemodynamic measurements, this premise cannot be definitely affirmed based on the present findings.

At the end of the experiment, while systolic pressure in rats with aortocaval shunts decreased to values comparable with their respective controls, diastolic pressure remained lower as did pulse pressure. This hemodynamic pattern indicates that the vascular shunt remained pervious in most ACF rats over the entire period of observation.

The decrease in CDP may have contributed to ongoing myocardial ischemia and necrosis with subsequent fibrosis repair, ultimately resulting in cardiac dysfunction. To the best of our knowledge, this is the first study to demonstrate in an experimental animal model of eccentric hypertrophy that CDP actually falls. It is likely that the CDP decrease persisted for longer than 1 week, since systemic diastolic pressure remained low until morphometric studies were performed. It remains to be demonstrated whether left ventricular end-diastolic pressure remains elevated.

The advent of cardiac hypertrophy was best demonstrated by myocyte enlargement occurring as early as 4 weeks following aortocaval fistula. Although the water content of lungs and liver was not increased, indicating that that overt heart failure did not occur in these ani- mals, this does not necessarily mean that cardiac function was not impaired. The absence of LV hemodynamic data before sacrifice precluded an accurate estimation of cardiac function at the end of experiment.

Cardiac remodeling at the nonmyocyte compartment was illustrated by a relative increase in fibrillar collagen deposition within the interstitial space as well as within the SE region. Accordingly, 2 types of cardiac fibrosis deposition were found in hearts of rats with aortocaval fistulas: reactive interstitial fibrosis and reparative SE fibrosis. ${ }^{19,37,38}$ Perivascular fibrosis was absent.

Although hemodynamics — phase 1 data were not significantly associated with the presence of myocardial fibrosis 4 weeks after aortocaval fistula, they correlated significantly with fibrosis found at 8 weeks. Among all hemodynamic variables, it was CDP that independently predicted SE fibrosis, whereas LV systolic and enddiastolic pressures independently predicted interstitial septal fibrosis. The association of decreased CDP during the early phases of hemodynamic derangement following aortocaval fistula creation with subsequent SE fibrosis has not been reported before. This fact suggests that SE fibrosis may conceivably be the consequence of impaired coronary perfusion. On the other hand, interstitial fibrosis appears to be consequence of LV overload. In this regard, the increase in interstitial fibrillar collagen presently observed does not differ from that reported to occur in different experimental models of cardiac hypertrophy in response to afterload increase. ${ }^{16,20}$

The increase in interstitial myocardial fibrosis in this model of aortocaval fistula is actually controversial..$^{24,27,28}$ It is conceivable to speculate that while LV hypertrophy is physiological and associated with preserved ventricular function, interstitial collagen remains relatively unchanged. In advanced stages characterized by cardiac dysfunction, it may be that collagen accumulates within the interstitial space. To confirm this hypothesis, hemodynamic measurements are to be repeated before the sacrifice of the animals. This investigation is presently under way.

In summary, hearts of rats submitted to volume overload consequent to aortocaval fistula creation show early reduction of LV coronary perfusion pressure and increased LV systolic and end-diastolic pressure. Subsequent LV remodeling is characterized by interstitial and SE fibrosis deposition. Subendocardial fibrosis was associated with coronary perfusion pressure and interstitial fibrosis with LV pressure.

\section{CONCLUSIONS}

Early hemodynamic changes appear to interfere with cardiac remodeling after aortocaval fistula creation. Impaired coronary perfusion pressure may contribute to SE fibrosis, and pressure overload to interstitial fibrosis.

\section{ACKNOWLEDGEMENTS}

We are grateful to Dr Beatriz Matsubara, from the Department of Cardiology - Faculty of Medicine of Botucatu (UNESP) for teaching the techniques involved in the experimental procedures and for giving us continuous support throughout the entire development of the investigation. We thank Fatima Abatepaulo for careful and dedicated work in histological procedures. We also thank Dr Maria de Lourdes Higuchi for providing the facilities of the Laboratory of Pathology, HCFMUSP for the analysis of some of the tissue sections. Research supported by Fundação Faculdade de Medicina, LIM-51-HC-FMUSP and FAPESP (02/00909-4). 
GUIDO MC e col. A redução da pressão de perfusão coronariana está associada com a fibrose endocárdica no modelo de hipertrofia por sobrecarga de volume em ratos. Rev. Hosp. Clín. Fac. Med. S. Paulo 59(4):228-235, 2004.

No remodelamento que se segue às sobrecargas de volume não é descrito o aumento de fibrose miocárdica. Após o infarto, entretanto, há hipertrofia do miocárdio remoto com acúmulo de fibrose, particularmente no subendocárdio. $\mathrm{Na}$ fístula aorto-cava, tal como no infarto, é possível que a queda da pressão de perfusão coronariana interfira com a fibrose cardíaca.

OBJETIVO: Investigar o papel das mudanças hemodinâmicas agudas sobre a fibrose cardíaca na fístula aorto-cava.

MÉTODO: Ratos Wistar submeti- dos a fístula aorto-cava, seguidos por 4 e 8 semanas, constituíram 4 grupos, fístula aorto-cava 4 e fístula aorto-cava 8 (10 ratos cada) e seus respectivos controles (sham-operated controls $\mathrm{Sh}), \mathrm{Sh} 4$ e Sh8 (8 ratos cada). A hemodinâmica foi realizada 1 semana após a cirurgia. A hipertrofia e a fibrose foram quantificadas ao final do seguimento pelo diâmetro dos miócitos e pela fração de volume do colágeno.

RESULTADOS: Comparados com Sh4 e Sh8, a pressão de pulso, a pressão diastólica final do ventrículo esquerdo e a $+\mathrm{dP} / \mathrm{dt}$ foram maiores em fístula aorto-cava 4 e fístula aorto-cava 8, enquanto a -dP/dt foi similar. A pressão estimada da perfusão coronariana $(\mathrm{mmHg})$ foi menor em fístula aortocava $8(52,6 \pm 4,1)$ do que em Sh 8 (100,8 $\pm 1,3)$, mas comparável entre fístula aorto-cava $4(50,0 \pm 8,9)$ e Sh4
$(84,8 \pm 2,3)$. O diâmetro dos miócitos foi maior em fístula aorto-cava 8 e a fibrose intersticial e subendocárdica maior em fístula aorto-cava 4 e fístula aorto-cava 8. Houve correlação inversa e independente da pressão de perfusão coronariana com a fibrose subendocárdica $\left(\mathrm{r}^{2}=0,86 ; \mathrm{p}<0,0001\right) \mathrm{e}$ das pressões sistólica $\left(r^{2}=0,73\right.$; $\mathrm{p}=0,0035)$ e diastólica final do ventrículo esquerdo $\quad\left(r^{2}=0,55\right.$; $\mathrm{p}=0.0124)$ com a fibrose intersticial.

CONCLUSÃO: A queda precoce da pressão de perfusão coronariana e o aumento das pressões ventriculares após a fístula aorto-cava associam-se com fibrose miocárdica subseqüente.

UNITERMOS: Fibrose miocárdica. Fístula aorto-cava. Pressão de perfusão coronariana. Sobrecarga de volume. Remodelamento cardíaco.

\section{REFERENCES}

1. Olivetti G, Cigola E, Maestri R, Lagrasta C, Corradi D, Quaini F. Recent advances in cardiac hypertrophy. Cardiovasc Res 2000;45:68-75.

2. Cohn JN, Ferrari R, Sharpe N. Cardiac remodeling - Concepts and clinical implications: a consensus paper from an international forum on cardiac remodeling. J Am Coll Cardiol 2000;35:569-82.

3. Doggrell SA, Brown L. Rat models of hypertension, cardiac hypertrophy and failure. Cardiovasc Res 1998;39:89-105.

4. Tomanek RJ. Response of coronary vasculature to myocardial hypertrophy. JACC 1990;15:528-33.

5. Bregagnollo EA, Rodrigues MA, Montenegro MR . Evolução temporal de medidas estruturais e funcionais da hipertrofia cardíaca desencadeada em ratos Wistar pela constrição da aorta abdominal. Arq Bras Cardiol 1986;46:9-17.

6. Strauer BE. Myocardial oxygen consumption in chronic heart disease: role of wall stress, hypertrophy and coronary reserve. Am J Cardiol 1979;44:730-40.

7. Colucci WS. Molecular and cellular mechanisms of myocardial failure. Am J Cardiol 1997;80(11A):15L-25L.

8. Anversa P, Ricci R, Olivetti G. Quantitative structural analysis of myocardium during growth and induced cardiac hypertrophy: a review. J Am Coll Cardiol 1986;7:1140-9.
9. Pereira V, de C, Rodrigues A, Tsutsui JM, Curi M, Mady C, Ramires J. Coronary flow velocity reserve in hypertensive patients with left ventricular systolic dysfunction. Clin Cardiol 2002; 25:95-102.

10. Brower GL, Janicki JS - Contribution of ventricular remodeling to pathogenesis of heart failure in rats. Am J Physiol Heart Circ Physiol 2001; 280:H674-H683.

11. Namba T, Tsutsui H, Tagawa H, Takahashi M, Saito K, Kozai T, et al. Regulation of fibrillar collagen gene expression and protein accumulation in volume-overloaded cardiac hypertrophy. Circulation 1997;95:2448-54.

12. Frimm CC, Koike MK, Cúri M. Subendocardial fibrosis in remote myocardium results from reduction of coronary driving pressure during acute infarction in rats. Arq Bras Cardiol 2003;80:515-20.

13. Norton GR, Woodiwiss AJ, Gaasch WH, Mela T, Chung ES, Aurigemma GP, et al. Heart failure in pressure hypertrophyThe relative roles of ventricular remodeling and myocardial dysfunction. J Am Coll Cardiol 2002;39:664-71.

14. Verdouw PD, van den Doel MA, de Zeeuw S, Duncker DJ. Animal models in the study of myocardial ischaemia and ischaemic syndromes. Cardiovasc Res 1998;39:121-35.

15. Aartsen WM, Schuijt MP, Danser AH, Daemen MJ, Smits JF. The role of locally expressed angiotensin converting enzyme in cardiac remodeling after myocardial infarction in mice. Cardiovasc Res 2002;56:205-13. 
16. Stilli D, Berni R, Sgoifo A, Costoli T, Bocchi L, Cacciani F, et al. Social stress, myocardial damage and arrhythmias in rats with cardiac hypertrophy. Physiology \& Behavior 2001;73:35158.

17. Liu Z, Hilbelink DR, Crockett WB, Gerdes AM. Regional changes in hemodynamics and cardiac myocyte size in rats with aortocaval fistulas. 1. Developing and established hypertrophy. Circ Res 1991;69:52-8.

18. Liu Z, Hilbelink DB, Crockett WB. Regional changes in hemodynamics and cardiac myocyte size in rats with aortocaval fistulas. 2. Long-term effects. Circ Res 1991;69:59-65.

19. Weber KT, Brilla CG, Janicki JS. Myocardial fibrosis: functional significance and regulatory factors. Cardiovasc Res $1993 ; 27: 341-8$.

20. Brilla CG, Weber KT. Reactive and reparative myocardial fibrosis in arterial hypertension in the rat. Cardiovasc Res 1992;26:6717

21. Weber KT, Brilla CG, Campbell SE, Reddy HK. Myocardial fibrosis and the concepts of cardioprotection and cardioreparation. J Hypertens 1992;10:S87-S94.

22. Weber KT, Brilla CG. Pathological hypertrophy and cardiac interstitium. Fibrosis and renin-angiotensin-aldosterone system. Circ Res 1991;83:1849-65.

23. Kamogawa Y, Biro S, Maeda M, Setoguchi M, Hirakawa T, Yoshida $\mathrm{H}$, et al. Dystrophin-deficient myocardium is vulnerable to pressure overload in vivo. Cardiovasc Res 2001;50:509-15.

24. Emery JL, Omens JH. Mechanical regulation of myocardial growth during volume-overload hypertrophy in the rat. Am J Physiol Heart Circ Physiol 1997;273:H1198-H1204.

25. Michel JB, Salzmann JL, Ossondo Nlom M, Bruneval P, Barres D, Camilleri JP. Morphometric analysis of collagen network and plasma perfused capillary bed in the myocardium of rats during evolution of cardiac hypertrophy. Basic Res Cardiol $1986 ; 91: 142-54$

26. Salzmann JL, Michel JB, Bruneval P, Ossondo Nlom M, Barres DR, Camilleri JP. Automated image analysis of myocardial collagen pattern in pressure and volume overload in rat cardiac hypertrophy. Anal Quant Cytol Histol 1986;8:326-32.

27. Narikawa S, Stefano LM, Georgetti JC . Quantificação da hipertrofia cardíaca e fibrose intersticial em corações de ratos submetidos a sobrecarga de pressão ou de volume. Rev Soc Cardiol Estado de São Paulo 2002;12(2):46.
28. Brower GL, Henegar JR, Janicki JS. Temporal evaluation of left ventricular remodeling and function in rats with chronic volume overload. Am J Physio Heart Circ Physiol 1996;40:H2071-H2078.

29. Frimm CC, Sun Y, Weber KT. Wound healing following myocardial infarction in the rat: role for bradykinin and prostaglandins. J Mol Cell Cardiol 1996;28:1279-85.

30. Frimm CC, Moraes AV, Medeiros C . Papel da pressão arterial casual e do exercício e a influência de fatores clínicos sobre a hipertrofia ventricular esquerda na hipertensão arterial. Arq Bras Cardiol 1994;63:21-6.

31. Perry GJ, Mori T, Wei CC, Xu XY, Chen YF, Oparil S, et al. Genetic variation in angiotensin-converting enzyme does not prevent development of cardiac hypertrophy or upregulation of angiotensin II in response to aortocaval fistula. Circulation 2001;103:1012-6

32. Garcia R, Diebold S. Simple. Rapid, and effective method of producing aortocaval shunts in the rat. Cardiovasc Res 1990;24:430-2.

33. Capasso JM, Li P, Zhang X, Anversa P. Heterogeneity of ventricular remodeling after acute myocardial infarction in rats. Am J Physiol Heart Circ Physiol 1992;262:H486-H495.

34. Cross C, Riechen P, Salisbury P. Coronary driving pressure and vasomotor tonus as determinants of coronary blood flow. Circ Res 1961;9:589-600.

35. Junqueira LC, Bignolas G, Brentani RR. Picrosirius staining plus polarization microscopy, a specific method for collagen in tissue sections. Histochem J 1979;11:447-55.

36. Wang X, Ren B, Liu S, Sentex E, Tappia PS, Dhalla NS. Characterization of cardiac hypertrophy and heart failure due to volume overload in the rat. J Appl Physiol 2003;94:75263.

37. Weber KT. Targeting pathological remodeling: concepts of cardioprotection and reparation. Circ Res 2000;102:1342-5.

38. Weber KT, Anversa P, Armstrong PW, Brilla CG, Burnett JC Jr, Cruickshank JM, et al. Remodeling and reparation of cardiovascular system. J Am Coll Cardiol 1992;20:3-16. 